\title{
Application of a Fluidic Actuator to Horizontal Directional Well Drilling
}

\author{
Jiangfu $\mathrm{He}$ \\ College of construction engineering \\ Jilin University \\ Changchun, People's Republic of China \\ E-mail: hejf11@mails.jlu.edu.cn
}

\author{
Xiaodong Zhao \\ Geotechnical Engineering Survey \\ Jiangsu Geotechnical Engineering co., LTD \\ Nanjing, People's Republic of China \\ E-mail: jsytgk@126.com
}

\author{
Kun Yin \\ College of construction engineering \\ Jilin University \\ Changchun, People's Republic of China \\ E-mail: yinkun@jlu.edu.cn \\ Houping Liu \\ Pipeline Research Institute of CNPC \\ China Petroleum Pipeline Bureau \\ Langfang, People's Republic of China \\ E-mail: fkwlhp@163.com
}

\begin{abstract}
-a hydraulic hammer with fluidic actuator was manufactured and applied to directional drilling due to the low penetration rate, long construction period and high drilling cost occurred during the operation of horizontal directional drilling in complicated formations, such as hard, fractured and cavy stratum. On the basis of hydraulic percussion rotary drilling technology, the hydraulic hammer has been innovatively designed and applied to trenchless drilling with horizontal directional wells, which is actuated and controlled by a fluidic amplifier. In addition, the actuator was tested in field by various pumped mud with different flow rates. Test results have implied that structure design of the whole drilling tools is qualified, and the pressure loss of fluidic actuator is permissible, which is suitable for the horizontal directional drilling of trenchless engineering project. Therefore, the original design of hydraulic hammer with fluidic actuator has solved the technical problem on horizontal directional drilling in complicated stratum, which has an excellent application value and promoted potential.
\end{abstract}

Keywords- Horizontal directional well; directional drilling; Fluidic actuator; Hydraulic hammer; Complicated stratum

\section{INTRODUCTION}

In recent years, trenchless drilling technology of horizontal directional wells has been extensively applied to engineering constructions with the rapid development of worldwide economics. However, the application of horizontal directional well drilling in a majority of middlesized and small cities is still insufficient [1]. With the limitation of complicated stratum condition, conventional drilling technology with directional well drilling in hard and fractured stratum can't meet the technical requirements of modern and urbanized development. Thus series of drilling problems have emerged in the operation of drilling process, such as low penetration rate, long construction period and high drilling cost, which absolutely has a great influence on the popularization and extensive application of trenchless drilling technology with horizontal directional wells $[2,3]$. In order to solve the crucial and technical problems of horizontal directional well drilling in hard and fractured stratum, it is necessary for drilling researchers to design and develop the new type of drilling tools of horizontal directional wells, which can be conveniently applied to complicated stratum conditions. Furthermore, there is an urgent need for the research on new drilling techniques and methods in the application of trenchless drilling technology with horizontal directional wells.

Due to many advantages like good quality of borehole, low drilling cost and less accidents emerging in drilling operation, the hydraulic percussion rotary drilling technology has been extensively applied to the exploration of solid mineral resource, hydrologic well drilling, oil and gas well drilling, thermal well drilling, geotechnical engineering construction drilling and other scientific drilling projects [4-6]. As the key part of the hydraulic hammer, the actuator is driven by water or mud with high pressure. In order to improve the service life of the fluidic actuator, and to promote the extensive application of hydraulic percussion rotary drilling technology, it has been the primary task for drilling researchers to conduct the study on hydraulic hammer and fluidic actuator [7].

Fluidic actuator was initially invented in 1970s, which was a great innovation for the development of hydraulic percussion and rotary drilling technology [8]. The hydraulic hammer is a new type of drilling tool for horizontal directional well drilling, and it is actuated by a bi-stable fluidic amplifier, which is termed as fluidic actuator, as shown in Fig. 1. The horizontal directional well drilling tool with hydraulic hammer is composed of top sub, fluidic amplifier, cylinder, piston, impact hammer, anvil, spline retainer and the bottom sub [9]. This new type of drilling tool has high energy efficiency and highly strong feasibility while drilling in complicated stratum condition. Furthermore, the hydraulic hammer has a stable performance while drilling in deep hole with high temperature and pressure $[10,11]$. Thus it is a potential drilling tool in the application of horizontal directional well drilling. In the meantime, the hydraulic hammer with 
a fluidic actuator can be used in the combination of screw motor drilling tool, and the integrated drilling tool with a fluidic actuator in hydraulic hammer has huge impact energy, which can be powered by a mud pump with high flow rate. Therefore, the drilling problem about long construction period, low penetration rate and high drilling cost can be resolved by the application of hydraulic hammer with a fluidic actuator while horizontal directional well drilling in hard and fractured stratum condition.

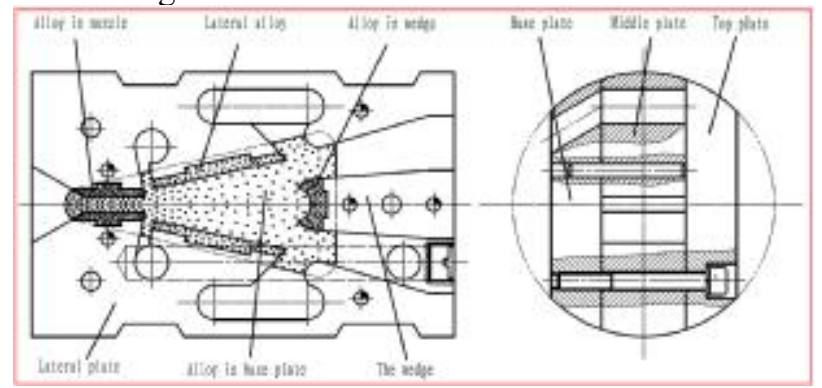

Figure 1. Schematic diagram of fluidic actuator in a horizontal directional drilling tool

\section{WORKING THEORY OF FLUIDIC ACTUATOR}

While drilling a horizontal directional well, the operating principle of a hydraulic hammer with fluidic actuator is shown as Fig. 2. The pumped mud with high pressure initially flows to the nozzle through drilling pipe, and then the mud is sprayed by the nozzle to generate a wall-attachment effect with high mud speed. It has been provided that the mud is attached to the upper chamber (as shown in green pipe line), the piston then is actuated by high pressure mud to horizontally impact the anvil, which is connected with the core barrel and drill bit. In the meantime, the controlled channel $\mathrm{F}$ is stimulated by a pressure pulse while the piston with hammer moves to the right dead point, simultaneously the discharge channel of high pressure mud is shifted from channel $\mathrm{E}$ to channel $\mathrm{C}$, thus the mud is pumped into the lower chamber, which actuates the piston to move back to return strokes. Therefore, the reciprocating impact energy transmission can be obtained by the periodic exchange of pumped mud in upper chamber and lower chamber. In addition, the circulated mud in upper and lower chamber will be discharged through the channel $\mathrm{C}$ and channel $\mathrm{E}$, and then be discharged to the annular space between the cylinder and drilling pipes. Eventually the mud will flow into the inner hole of core barrel and the drill bit, thus the drill bit is cooled and the bottom of borehole is cleaned.

\section{STRUCTURE DESIGN OF DRILLING TOOL}

The structure of hydraulic hammer with a fluidic actuator is complicated, which is purposely used in horizontal directional well drilling. The whole drilling tool is mainly composed of fluidic actuator, piston, cylinder, external pipe, hammer and the anvil. In order to meet the requirement on impact energy efficiency, the technical requirements of huge impact energy and small impact frequency must be taken consideration in the design of horizontal directional well drilling tool. Thus the impact hammer and the anvil of horizontal directional well drilling tool must be optimally designed. In addition, the impact stroke and motion frequency of the piston can be adjusted by a replaceable rod, and the relevant impact stroke of a single adjusting rod is show as Table I.

TABLE I. THE IMPACT STROKE AND MOTION FREQUENCY OF HYDRAULIC

\begin{tabular}{|c|c|c|c|c|c|c|}
\hline $\begin{array}{c}\text { Length of adjusting } \\
\text { rod (mm) }\end{array}$ & $\mathbf{9 0}$ & $\mathbf{1 0 0}$ & $\mathbf{1 1 0}$ & $\mathbf{1 2 0}$ & $\mathbf{1 3 0}$ & $\mathbf{1 4 0}$ \\
\hline $\begin{array}{c}\text { Impact stroke (mm) } \\
\text { Motion } \\
\text { frequency ( Hz) }\end{array}$ & 10 & 11 & 12 & 14 & 16 & 18 \\
\hline
\end{tabular}

The material of horizontal directional well drilling tool is selected as $35 \mathrm{CrMo}$, and the mechanical properties of $35 \mathrm{CrMo}$ are qualified. In order to enhance the abrasive resistance of the fluidic actuator and extend the service life of horizontal directional well drilling tool, the fluidic actuator is partially inlayed with hard alloy, as shown in Fig. 1.

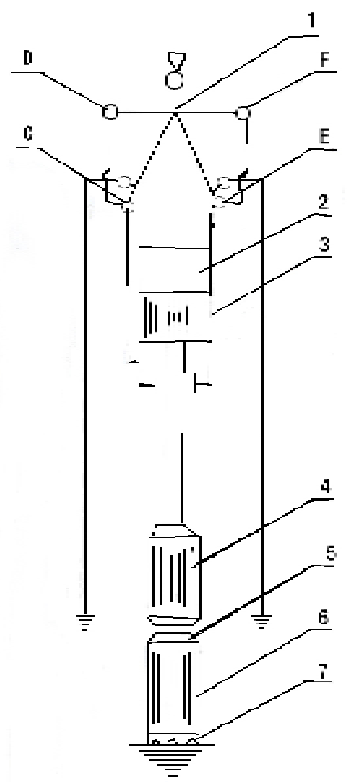

Figure 2. Schematic diagram of a hydraulic hammer with fluidic actuator C, E: Discharge channel; D, F: Controlled flow channel

\section{FIELD TEST}

The field tests have been conducted once the structure of the hydraulic hammer with a fluidic actuator was optimized. Furthermore, the feasible configuration of auxiliary drilling tools has been utilized during the field tests. In addition, a group of flow rates have been pumped into the hydraulic hammer to actuate the hammer impacting the anvil, and the working frequency of the hammer and the pressure loss of the actuator are monitored and recorded by a computer. The field test results are analyzed according to the feasibility of hydraulic hammer with a fluidic actuator to horizontal directional well drilling. The scheme diagram of drilling system in horizontal directional well drilling is shown in Fig. 3. 


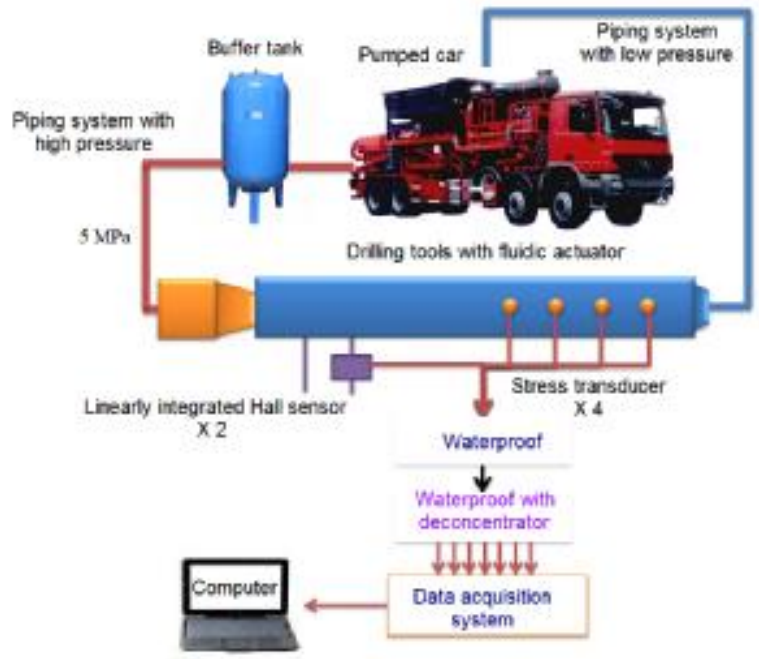

Figure 3. Scheme diagram of drilling system in field tests

\section{RESULTS}

As shown from Fig. 4 to Fig. 8, the pressure variation of hydraulic hammer with a fluidic actuator is monitored by the data acquisition system. While the pumped flow rate is $10 \mathrm{~L} / \mathrm{s}$, the maximum pressure of the fluidic actuator is $1.78 \mathrm{MPa}$, and the minimum pressure is approximately 0 , thus the pressure loss of the actuator is nearly $1.78 \mathrm{MPa}$, which is acceptable for the performance of mud pump in directional well drilling.

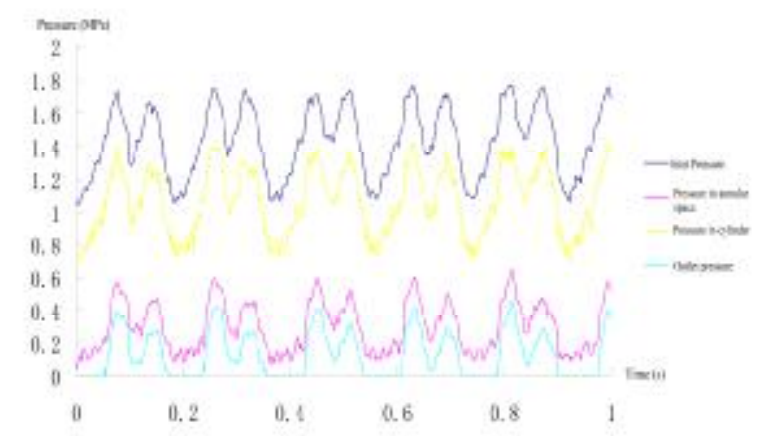

Figure 4. Variation on pressure in the hydraulic hammer with a fluidic

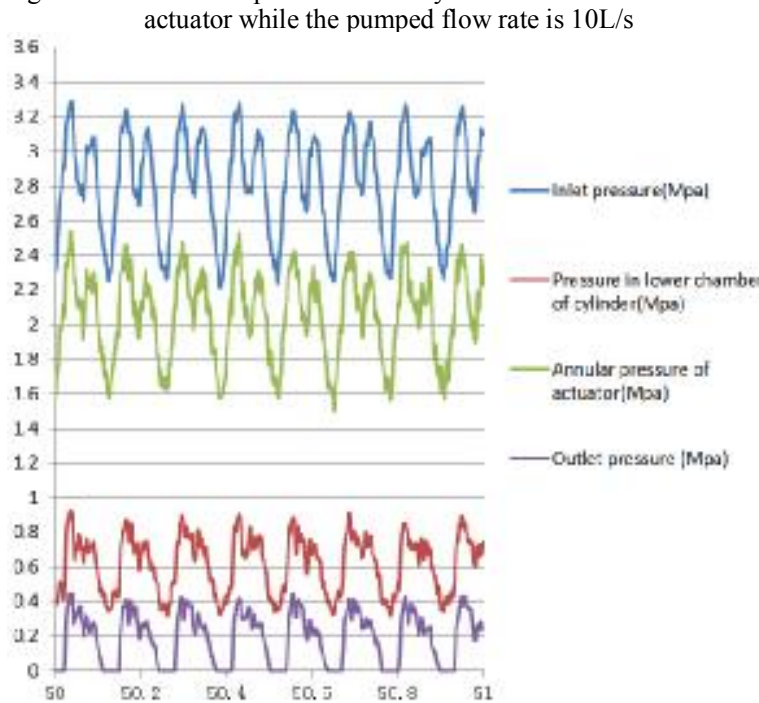

Figure 5. Variation on pressure in the hydraulic hammer with a fluidic actuator while the pumped flow rate is $12 \mathrm{~L} / \mathrm{s}$

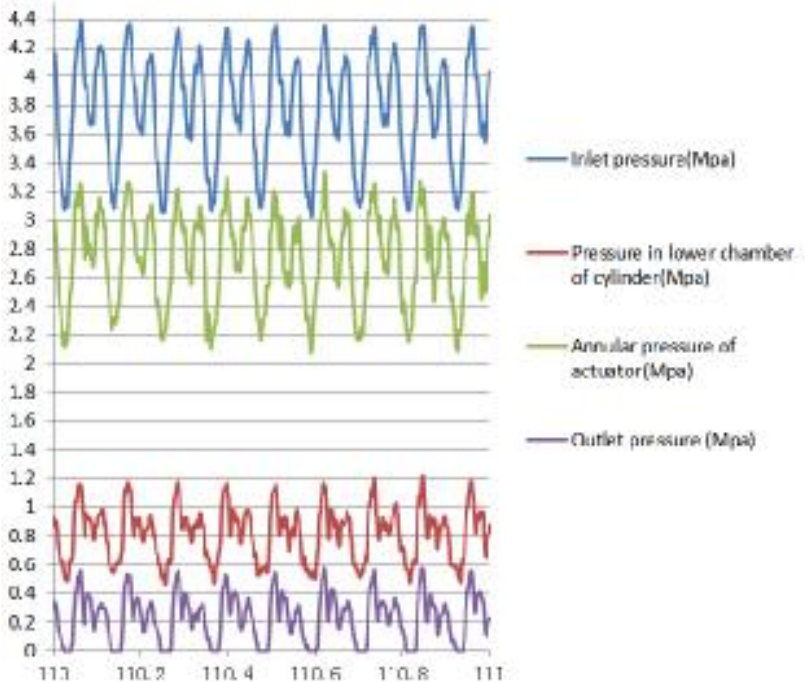

Figure 6. Variation on pressure in the hydraulic hammer with a fluidic actuator while the pumped flow rate is $14 \mathrm{~L} / \mathrm{s}$

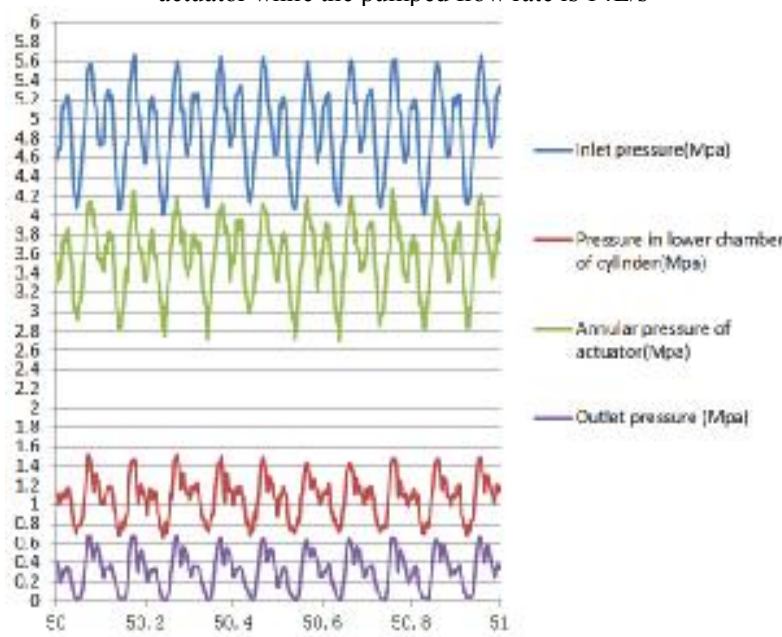

Figure 7. Variation on pressure in the hydraulic hammer with a fluidic actuator while the pumped flow rate is $16 \mathrm{~L} / \mathrm{s}$

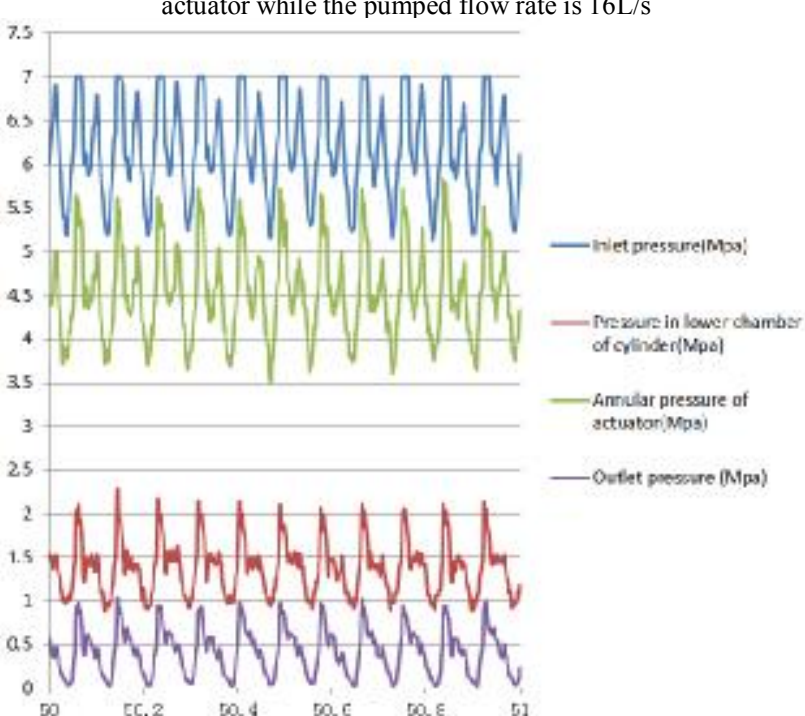

Figure 8. Variation on pressure in the hydraulic hammer with a fluidic actuator while the pumped flow rate is $18 \mathrm{~L} / \mathrm{s}$

It can be concluded that, as shown in Fig. 9, with the increasing of pumped flow rate, the pressure loss of the fluidic actuator is simultaneously varying, thereby the working load of the hydraulic hammer is increasing, which can reduce the service life of the drilling tool with a 
hydraulic hammer. Therefore, the pumped flow rate of the mud should be controlled in order to improve the service life of fluidic actuator.

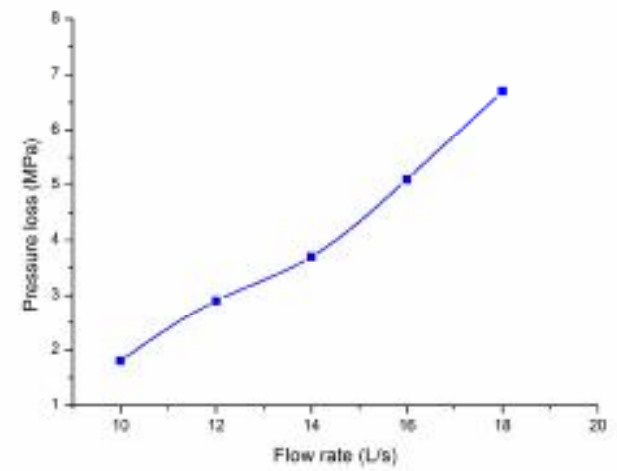

Figure 9. Pressure loss variation of the fluidic actuator with various pumped flow

According to the working frequency variation in Fig. 10 , it can be concluded that the maximum working frequency of hydraulic hammer with a fluidic actuator is $10 \mathrm{~Hz}$ while the pumped flow rate is $16 \mathrm{~L} / \mathrm{s}$, which is applicable to horizontal directional well drilling. It can be concluded that low working frequency of hydraulic hammer have heavy impact energy while drilling in horizontal directional wells. Therefore, the innovative design of fluidic actuator is feasible to the horizontal directional well drilling while in energy exploration and prospect.

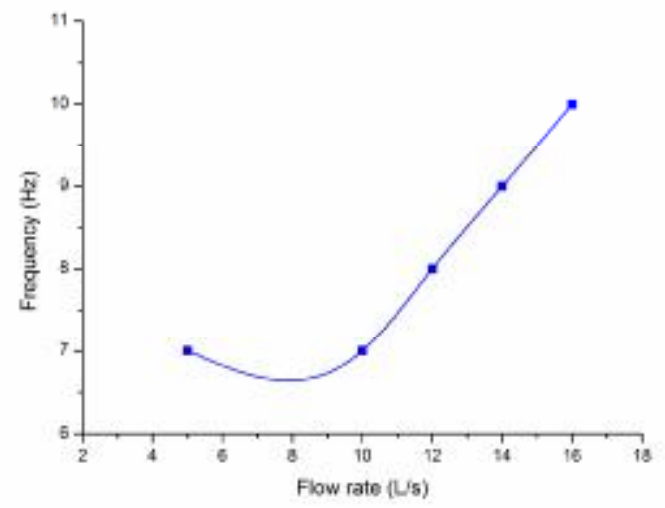

Figure 10. Working frequency variation of the fluidic actuator with the pumped flow Rate

\section{CONCLUSIONS}

1. Horizontal directional well drilling tool with a fluidic actuator has been innovatively designed, which is feasible to the application of trenchless drilling with directional wells;

2. The structures of the fluidic actuator and the hydraulic hammer have been optimized in order to obtain the optimal impact energy efficiency and service life;

3. Feasible configuration of drilling tools has been proposed, which is applicable to horizontal directional well drilling.

\section{ACKNOWLEDGMENT}

This work was financially supported by Geological Survey Project of China Geological Survey (Project NO. 12120113096900) and Natural Science Foundation of China (Project NO. 40904052).

\section{REFERENCES}

[1] Liu Qiang, "A study on pipeline installation technology of horizontal directional drilling in rock", Ph.D dissertation, 2009.

[2] Chapman. D.N. , "No-dig international trenchless systems- an industry overview". Installation Techniques No-dig International. Vol. 5 1994:14-160, 1994.

[3] Huang Yongshuo, "Hydraulics study of under-balance method for trenchless horizontal directional drilling in pipeline crossing", Master's thesis, 2012.

[4] J.M. Peng, "Numerical experimental study of a liquid jet hammer with energy-saving mechanism". Ph.D dissertation, 2004.

[5] F.J. Tan, "The retrofit design of fluid efflux hammer and its Matlab simulation computation". Ph.D dissertation, 2005.

[6] J.W. Chen, "Research on simulation computation and experiment of liquid jet hammer". Ph.D dissertation, 2007.

[7] Wu Peng, Z.L. Wei, Zhang bin, Ou Lin, "The application of a new liquid jet hammer". Journal of Guangzhou University, Vol 24 No.3, Sep. 2012.

[8] Kun Yin, M.S. Wang, J.M. Peng, R.S. Wang, Percussion and rotary drilling, Geological Press, Beijing, 2010.

[9] Liu He "Theoretical analysis and experimental research on liquid jet oscillation tool". Ph. D dissertation, 2014.

[10] J.F. He, J.M. Peng, X.X. Zhang, "Design and feasibility analysis of a fluidic jet oscillator for reduction of friction and drag torque in horizontal directional drilling". Sensors and Actuators A: Physical, unpublished.

[11] Chen Chen, "Research on the modification of jet hydraulic impactor rod". Master's thesis, 2009. 